\title{
Persistent Hypocalcemia after Thyroidectomy Stabilized with Magnesium
}

\author{
Alvaro Contreras Salazar ${ }^{1 \star}$, Jesús Armando Del Moral Bastida ${ }^{2}$, Hugo Mendieta Zerón ${ }^{1,2}$
}

${ }^{1}$ Faculty of Medicine, Autonomous University of the State of Mexico (UAEMéx), MEXICO
${ }^{2}$ "Mónica Pretelini Sáenz" Maternal-Perinatal Hospital and Ciprés Grupo Médico (CGM), MEXICO
^Corresponding Author: drmendietaz@yahoo.com

Citation: Contreras Salazar A, Del Moral Bastida JA, Mendieta Zerón H. Persistent Hypocalcemia after Thyroidectomy Stabilized with Magnesium. Electron J Gen Med. 2020;17(5):em220. https://doi.org/10.29333/ejgm/7883

\section{ARTICLE INFO}

Received: 3 Feb. 2020

Accepted: 16 Mar. 2020

\begin{abstract}
We present the case of a 53-year-old woman who underwent total thyroidectomy as a multinodular goiter treatment, which after surgery presented hypocalcemia that did not reverse with combined therapy of calciotropic hormones and calcium supplementation. The symptomatology remission was reached only after the prescription of magnesium lactate tablets. It is known that hypocalcemia is the main complication of this surgery, however, little is known about hypomagnesemia and its role as a cause and consequence of the imbalance in calcium homeostasis in this kind of patients. The clinical and biochemical evolution of the patient is evaluated, as well as the pathophysiology of hypocalcemia due to magnesium deficiency that involves a large number of processes such as renal, intestinal and bone function.
\end{abstract}

Keywords: hypocalcemia, hypomagnesemia, thyroidectomy

\section{INTRODUCTION}

Calcium homeostasis is regulated by several metabolic processes that keep a plasma concentration of calcium within narrow limits, ranging between 8.8 and $10.4 \mathrm{mg} / \mathrm{dl}$. In general, these processes are orchestrated by parathyroid hormone (PTH), thyroid hormone, vitamin D, calcitonin, phosphorus and magnesium. The role played by the latter, unlike the other factors involved, is poorly understood (1).

Magnesium depletion has been associated with parathyroid activity deterioration and subsequent hypocalcemia. This phenomenon may be due to a failure in the production or release of PTH, reduced bone response to this hormone, bone resistance to vitamin $\mathrm{D}$, increased calcitonin action or to a primary change bone crystals solubility, growth rate or dissolution (2).

Patients undergoing total thyroidectomy as a treatment for several types of malignant or benign nodules develop hypocalcemia as main postsurgical complication, which is often accompanied by hypomagnesemia. It has been shown that a significant decrease in magnesium levels after surgery is significantly associated with the development of permanent hypocalcemia $(3,4)$.

\section{CASE REPORT}

A 53-year-old female patient assisted to the Endocrinology and Internal Medicine consultation in November 2017, describing pain in the right hemithorax and lower limbs. Initial laboratories showed triglycerides of $440 \mathrm{mg} / \mathrm{dl}$, thyroid ultrasound with multinodular goiter and thyroid scan with similar abnormalities. The fine needle biopsy revealed atypia of uncertain significance with follicular lesions of Hürthle cells.

She was submitted to total thyroidectomy on April 16, 2018. In the postoperative period, the patient presented hypocalcemia $(6.7 \mathrm{mg} / \mathrm{dl})$ with serum albumin of $3.5 \mathrm{~g} / \mathrm{dl}$, and corrected calcium of $7.1 \mathrm{mg} / \mathrm{dl}$. The patient was treated with 5 tablets of caltrate $600+M$ every 8 hours, calcitriol $0.25 \mu \mathrm{g}$ every 12 hours and PTH sc $20 \mu$ g every 24 hours. Due to persistent hypocalcemia, 1 tablet of Limagal (magnesium lactate) $750 \mathrm{mg}$ was added every 8 hours. 21 days later the serum calcium increased to $9.2 \mathrm{~g} / \mathrm{dl}$. Four weeks later the patient suspended the magnesium lactate, with posterior appearance of distal paresthesias in lower limbs with multiple involuntary muscle contractions. Therefore, the magnesium lactate had to be restored, correcting immediately the clinical manifestations.

\section{DISCUSSION}

The case of this patient is a clear example of what happened in patients undergoing thyroidectomy regarding their calcium levels and the management they should receive for the correction of the alterations. However, there is still no established consensus on the pathophysiology of this process, and although several mechanisms have been proposed, which will be discussed below, none fully explains the role of magnesium in calcium homeostasis.

An essay published in 1973 by Reddy CR et al., which consisted of assessing serum calcium levels in chicks with and 
without magnesium deficiency, points to two pathophysiological mechanisms: 1) Altered calcium balance between the extracellular environment and the bone, favoring displacement towards the latter. This event is evidenced by observing an increase in cortical bone thickness and decrease in lytic areas, 2) Parathyroid gland dysfunction or lack of response to PTH probably due to the presence of an excess of osteoid tissue, phenomenon that can be confirmed by high serum phosphate concentration (5).

Another study conducted in dogs in 1979 by Freitag et al., in which the PTH response was evaluated in perfused bone isolated from a control population of dogs with a normal diet and another population fed with a reduced magnesium diet, showed evidence of bone resistance to this hormone, reinforcing what was published by Reddy et al. (2). In the study of Freitag, the lack of bone response to b-PTH 1-34 was demonstrated by measuring CAMP levels, a metabolite generated in response to the action of PTH in its target tissues, which showed to be markedly lower in the population of dogs with a magnesium deficient diet. This strategy to evaluate PTH activity is still valid and very useful when evaluating patients with suspected hypoparathyroidism, as well as to establish the subtype of the condition (6).

Because the adenylate cyclase activity is magnesium dependent, which makes it possible for chronic depletion of this ion to affect the activity of this enzyme. Despite the lower CAMP production by magnesium-deficient bone is a convincing explanation, it does not satisfy the fact of the reduced PTH synthesis in cases of magnesium-deficient bones (7).

While most literature notes that magnesium acts as a PTH secretion cofactor by sensitizing the calcium receptor, it has also been shown that a slight reduction in serum magnesium concentration can stimulate PTH release; while more severe depletion can affect its production. These facts suggest that magnesium is involved, rather than in the release of the hormone, in its production. This phenomenon can be achieved by regulating the 1,25-hydroxyvitamin $D$ synthesis, which acts on the vitamin D receptor (VDR) promoting the PTH mRNA transcription (8).

That said, the most convincing explanation for hypocalcemia that occurs in magnesium depletion, is the reduced calcium mobilization from the bone, because of both the decrease in PTH levels and the action on target tissues (7).

A similar observation to this case report was described in a work carried out by Chase et al. in which three patients with hypocalcemia due to hypomagnesemia were evaluated. All subjects had levels in the normal/low PTH range, markedly low levels of calcium and magnesium, as well as clinical signs such as carpal-pedal spasm. An attempt was made to modify the state of the patients by administering intravenous calcium, thereby reversing the carpal-pedal spasm and calcium levels were normalized, but a while after the infusion was suspended, calcium levels fell below normal values again. The condition reversed only after restoring magnesium (9).

The previous study suggests that hypocalcemia in hypomagnesaemic subjects, results primarily from reduced magnesium and calcium exchange on bone surfaces. Moreover, it has been hypothesized that hypocalcemia is perpetuated by a lack of efficient PTH secretion in response to hypocalcemia and possible refractoriness to its effects on the bone, but not on the kidney or intestine. The first mechanism can be directly attributed to hypomagnesemia, while the latter is rather secondary to the decreased mineralization of the new osteoid formed secondary to hypocalcemia (9).

In patients with hypoparathyroidism, the main biochemical finding is hypocalcemia with a low or inappropriately normal concentration of PTH. In addition, most hypoparathyroid patients have elevated levels of phosphorus, 25-hydroxyvitamin D in normal ranges, normal or low 1,25-hydroxyvitamin $\mathrm{D}$, elevated creatinine levels and magnesium in normal or low range (10).

Normal levels of 25-hydroxyvitamin D and 1,25hydroxyvitamin D, low PTH levels (essential for the hydroxylation of vitamin $D$ in the kidney to convert it to its active form: 1,25-hydroxyvitamin D) and the depletion of magnesium, which is involved in the correct action of these hormones, explain why the administration of calciotropic hormones without the replacement of magnesium does not reverse hypocalcemia. It has also been demonstrated both low PTH secretion and elevated catabolism in the liver and kidneys in cases of hypomagnesemia (11).

It has also been proposed that magnesium acts as a cofactor of the enzyme 25-hydroxyvitamin D-1 a-hydroxylase, which explains that the PTH administration in situations of hypomagnesemia fails to properly raise the levels of 1,25 hydroxyvitamin $\mathrm{D}(12)$.

There are certain risk factors for developing hypocalcemia and hypomagnesemia after a total thyroidectomy: age ( $>40$ years), female sex, hyperthyroidism (hyperthyroid patients have been shown to have low magnesium levels, as well as increased urinary excretion of magnesium), greater extent of surgery, postoperative PTH $<8 \mathrm{pg} / \mathrm{ml}$, postoperative magnesium $<1.8 \mathrm{mg} / \mathrm{dl}$, low preoperative levels of vitamin $\mathrm{D}$ and hemodilution (2).

Other situations related to hypomagnesemia are the consumption of proton pump inhibitors, since the reduction in stomach acidity decreases the absorption of magnesium, and teriparatide (PTH analogous) administration, documented in osteoporotic patients, which results paradoxical since this drug has been used successfully to treat post-surgical hypoparathyroidism severe cases (13-15).

PTH stimulates the magnesium reabsorption in the kidney and small intestine, and also causes the magnesium release from the bone by enhancing osteoclastic activity. These actions result in an increase in serum magnesium levels. In the setting of hypoparathyroidism, absence or low PTH circulating levels lead to hypocalcemia by impairing osteoclast activity, which diminishes the calcium efflux from bone, by enhancing urinary calcium excretion and by inhibiting the renal synthesis of calcitriol, which impairs the intestinal absorption of dietary calcium $(10,16)$.

Calcium and phosphate homeostasis is also regulated by fibroblast growth factor 23 (FGF23), an osteocyte-derived hormone that inhibits renal tubular phosphate reabsorption and the renal synthesis of calcitriol. Deficiency of PTH also causes hyperphosphatemia, owing to an increase in the renal tubular reabsorption of phosphate (10). Hyperphosphatemia is relevant since, by itself, is related to long-term complications seen in hypoparathyroidism such as central nervous system calcifications, and directly diminish PTH secretion by altering the response of the calcium-sensing receptor $(17,18)$.

Some authors emphasize the importance of postoperative measurement of PTH and the fact that a decrease in their levels can predict the development of hypocalcemia due to 


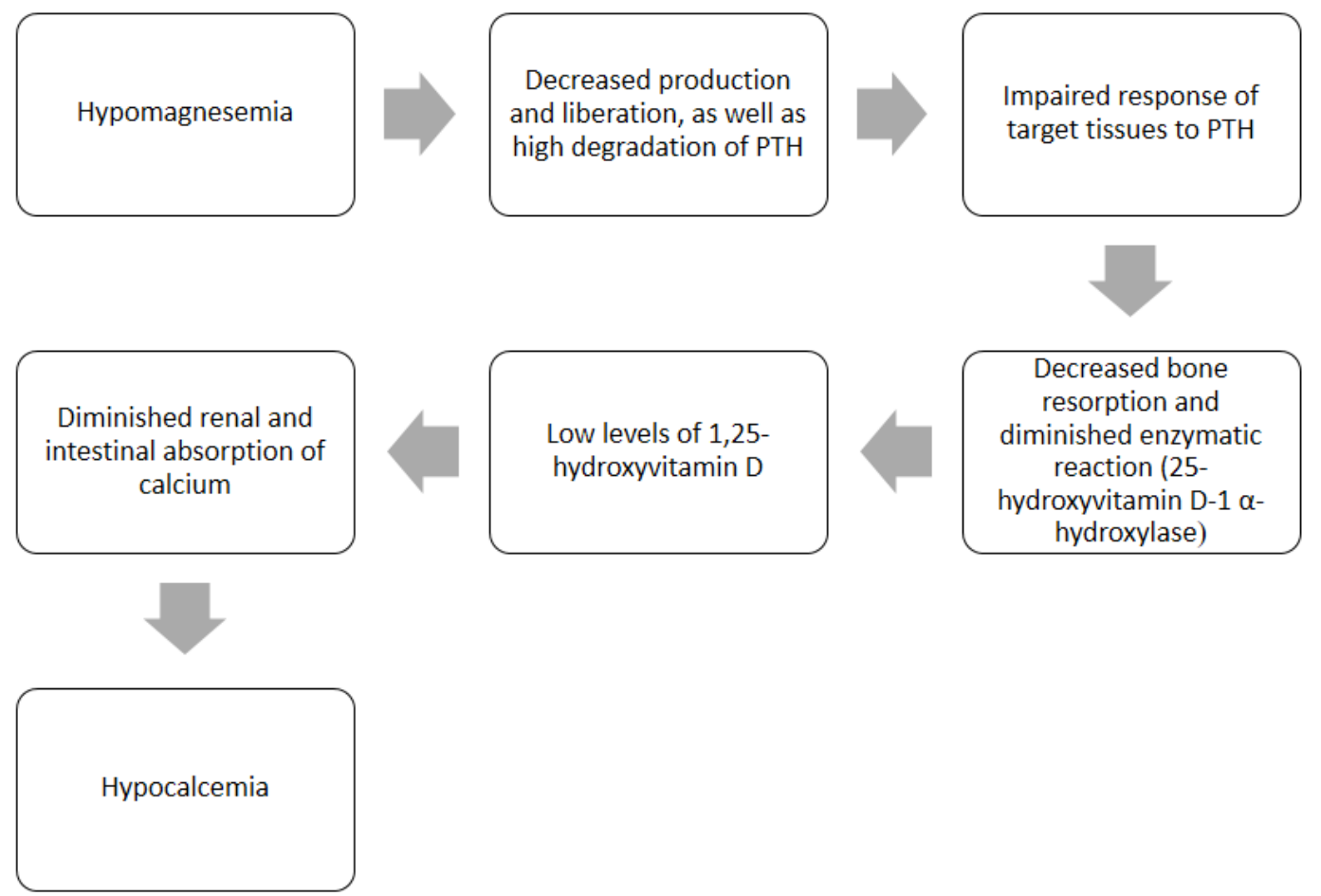

Figure 1. Simplified process of the pathophysiology of hypocalcemia due to hypomagnesemia

thyroidectomy (19). When symptoms occur after thyroidectomy, both calcium and magnesium should be corrected and monitored (20). Thus, the measurement of calcium, magnesium, PTH and thyroid hormones is proposed in patients with risk factors who will undergo surgery. Autotransplantation of inferior parathyroid glands must always be considered, because it provides lower incidence of permanent hypoparathyroidism (21).

\section{CONCLUSIONS}

Hypocalcemia is a frequent complication in radical thyroidectomy. It is thus said that magnesium plays a crucial role in calcium homeostasis, both in healthy subjects and in the postoperative period.

The mechanisms involved in hypocalcemia due to magnesium depletion are diverse and not yet well understood, among which are: defect in the production and secretion of PTH, decreased enzyme activity such as the enzyme 25hydroxyvitamin D-1 $\alpha$-hydroxylase involved in the regulation of calciotropic hormones, displacement of calcium from the extracellular medium to the bone, reduced bone turnover, increased PTH catabolism and resistance to the PTH action in target tissues (Figure 1).

It has also been proposed that hypomagnesemia is both a cause and a consequence of hypocalcemia due to the actions that PTH has on the homeostasis of this ion.

Risk factors to develop hypomagnesemia and hypocalcemia after thyroidectomy have been identified, such as; age over 40 years; female gender; hypothyroidism; hyperthyroid patients have increased urinary excretion of magnesium; chronic consumption of proton pump inhibitors, and consumption of teriparatide.

It is necessary to measure and keep a constant monitoring of magnesium values before and after surgery to intervene on time and avoid hypocalcemic states, especially in patients with risk factors.

\section{REFERENCES}

1. Shifrin A. Chapter 6 - Brief Overview of Calcium, Vitamin D, Parathyroid Hormone Metabolism, and Calcium-Sensing Receptor Function. In: Shifrin AL, editor. Advances in Treatment and Management in Surgical Endocrinology. Elsevier; 2020:63-70. Available at: https://www.elsevier. com/books/advances-in-treatment-and-management-insurgical-endocrinology/shifrin/978-0-323-66195-9

2. Cherian AJ, Gowri M, Ramakant P, Paul TV, Abraham DT, Paul MJ. The Role of Magnesium in Post-thyroidectomy Hypocalcemia. World J Surg. 2016;40(4):881-8. https://doi. org/10.1007/s00268-015-3347-3 PMID:26578317

3. Luo H, Yang H, Zhao W, Wei T, Su A, Wang B, et al. Hypomagnesemia predicts postoperative biochemical hypocalcemia after thyroidectomy. BMC Surg. 2017;17(1):62. https://doi.org/10.1186/s12893-017-0258-2 PMID:28545530

4. Garrahy A, Murphy MS, Sheahan P. Impact of postoperative magnesium levels on early hypocalcemia and permanent hypoparathyroidism after thyroidectomy. Head Neck. 2016;38(4):613-9. https://doi.org/10.1002/hed.23937 PMID: 25491348

5. Reddy CR, Coburn JW, Hartenbower DL, Friedler RM, Brickman AS, Massry SG, et al. Studies on Mechanisms of Hypocalcemia of Magnesium Depletion. J Clin Invest. 1973;52(12):3000-10. https://doi.org/10.1172/JCl107498 PMID:4750437 
6. Bilezikian J, Khan A, Potts J, Brandi M, Clarke B, Shoback D, et al. Hypoparathyroidism in the Adult: Epidemiology, Diagnosis, Pathophysiology, Target Organ Involvement, Treatment, and Challenges for Future Research. J Bone Miner Res. 2011;26(10):2317-37. https://doi.org/10.1002/ jbmr.483 PMID:21812031

7. Freitag JJ, Martin KJ, Conrades MB, Bellorin-Font E, Teitelbaum S, Klahr S, Slatopolsky E. Evidence for Skeletal Resistance to Parathyroid Hormone in Magnesium Deficiency. J Clin Invest. 1979;64(5):1238-44. https://doi.org/10.1172/JCI109578 PMID:227929.

8. Naveh-Many T, Silver J, Kronenberg HM. Chapter 24 Parathyroid hormone molecular biology. In: Bilezikian JP, Martin TJ, Clemens TL, Rosen CJ, Editor(s). Principles of Bone Biology (Fourth Edition) Academic Press, 2020:57594. Available at: https://www.elsevier.com/books/ principles-of-bone-biology/bilezikian/978-0-12-373884-4

9. Chase LR, Slatopolsky E, Krinski T. Secretion and Metabolic Efficacy of Parathyroid Hormone in Patients with Severe Hypomagnesemia. J Clin Endocrinol Metab. 1974;38(3):363-71. https://doi.org/10.1210/jcem-38-3-363 PMID:4360918.

10. Mannstadt M, Bilezikian JP, Thakker RV, Hannan FM, Clarke BL, Rejnmark L, et al. Hypoparathyroidism. Nat Rev Dis Primer. 2017;3(1):1-21. https://doi.org/10.1038/nrdp.2017. 55 PMID:28857066

11. Mori S, Harada S, Okazaki R, Inoue D, Matsumoto T, Ogata E. Hypomagnesemia with increased metabolism of parathyroid hormone and reduced responsiveness to calcitropic hormones. Intern Med. 1992;31(6):820-4. https://doi.org/10.2169/internalmedicine.31.820 PMID: 1392187

12. Fatemi S, Ryzen E, Flores J, Endres DB, Rude RK. Effect of experimental human magnesium depletion on parathyroid hormone secretion and 1,25-dihydroxyvitamin D metabolism. J Clin Endocrinol Metab. 1991;73(5):1067-72. https://doi.org/10.1210/jcem-73-5-1067 PMID:1939521

13. Cantillano Rodríguez SN, Casasola Vargas JC, Rivera Zetina DJ. Hipomagnesemia asociada con inhibidores de bomba de protones. Med Int Méx. 2013;29(1):62-6. Available at: https://www.medigraphic.com/pdfs/medintmex/mim2013/mim131k.pdf
14. Bégin M-J, Ste - Marie L-G, Coupal L, Ethier J, Räkel A. Hypomagnesemia During Teriparatide Treatment in Osteoporosis: Incidence and Determinants. J Bone Miner Res. 2018;33(8):1444-9. https://doi.org/10.1002/jbmr.3438 PMID:29637622

15. Kitaigrodsky AV, Diehl M, Galich AM, Lovazzano S, Santangelo L, Giunta D, et al. Tratamiento prolongado con teriparatida en el hipoparatiroidismo grave de difícil manejo. Actual. Osteol 2015;11(2):114-24. Available at: http://osteologia.org.ar/files/pdf/rid42_2.pdf

16. Ambrogini E, Jilka RL. Chapter 32 - Cellular actions of parathyroid hormone on bone. In: Bilezikian JP, Martin TJ, Clemens TL, Rosen CJ, Editor(s). Principles of Bone Biology (Fourth Edition) Academic Press, 2020, p. 775-88. Available at: https://www.elsevier.com/books/principles-of-bonebiology/bilezikian/978-0-12-373884-4

17. Legati A, Giovannini D, Nicolas G, López-Sánchez U, Quintáns B, Oliveira JRM, et al. Mutations in XPR1 cause primary familial brain calcification associated with altered phosphate export. Nat Genet. 2015;47(6):579-81. https://doi.org/10.1038/ng.3289 PMID:25938945

18. Centeno PP, Herberger A, Mun H-C, Tu C, Nemeth EF, Chang $W$, et al. Phosphate acts directly on the calcium-sensing receptor to stimulate parathyroid hormone secretion. Nat Commun. 2019;10(1):1-12. https://doi.org/10.1038/s41467019-12399-9 PMID:31619668

19. Martin S, Parfeni O, Mustata T, Andrei M, Sirbu A, Barbu C, et al. Postoperative Hypoparathyroidism in Patients After Total Thyroidectomy - Experience of a Tertiary Center in Romania. Chirurgia (Bucur). 2019;114(5):602. https://doi. org/10.21614/chirurgia.114.5.602 PMID:31670636.

20. Wang W, Meng C, Ouyang Q, Xie J, Li X. Magnesemia: an independent risk factor of hypocalcemia after thyroidectomy. Cancer Manag Res. 2019;11:8135-44. https://doi.org/10.2147/CMAR.S218179 PMID:31564973

21. Wei T, Li Z, Jin J, Chen R, Gong Y, Du Z, et al. Autotransplantation of Inferior Parathyroid glands during central neck dissection for papillary thyroid carcinoma: A retrospective cohort study. Int J Surg. 2014;12(12):1286-90. https://doi.org/10.1016/j.ijsu.2014.11.001 PMID:25448646 